\title{
Majorana Thermosyphon Prototype Experimental Results
}

\author{
JE Fast DJ Reid \\ E Aguayo
}

December 2010

\section{Pacific Northwest}

NATIONAL LABORATORY

Proudly Operated by Battelle Since 1965 


\section{Majorana Thermosyphon Prototype Experimental Results}

JE Fast

DJ Reid

E Aguayo

December 2010

Prepared for

the U.S. Department of Energy

under Contract DE-AC05-76RL01830

Pacific Northwest National Laboratory

Richland, Washington 99352 


\begin{abstract}
This report presents the experimental results of PNNL's MAJORANA DEMONSTRATOR prototype cooling system. The MAJORANA DEMONSTRATOR high-purity germanium (HPGe) detector modules should operate as close to liquid nitrogen temperature as possible to provide adequate cooling for a full range of HPGe impurity concentrations. In addition, exceptional temperature stability $(<1 \mathrm{~K})$ is needed to reduce electronic gain shifts due to changes in the front end FET operating temperature. One approach is to use the two-phase liquid-gas equilibrium to ensure constant temperature. The MAJORANA DEMONSTRATOR cooling system is required to transport the heat $\sim 1$ meter from the detectors located inside a lead and copper shield to a liquid nitrogen Dewar outside the shield. Two-phase cooling results in near zero temperature difference over this distance in contrast to the several degrees Kelvin that would result from a system that conducts the heat through a massive copper cold finger. Furthermore, the tube required for a two-phase system can more readily be produced by electroforming (required for radiopurity) than a massive cold finger. A nitrogen thermosyphon can be designed so the vaporization/condensation process transfers heat through the shield while maintaining a stable operating temperature. A prototype of such a system has been built and tested at PNNL. This document presents the experimental results of the prototype and evaluates the heat transfer performance of the system.
\end{abstract}




\section{Contents}

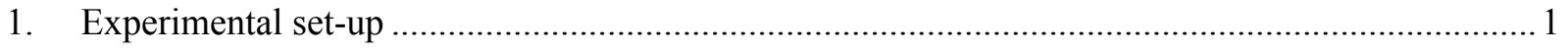

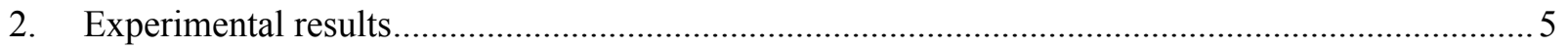

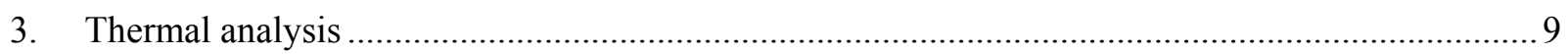

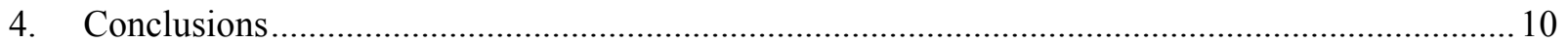

Appendix A: Convective heat transfer calculations for the thermosyphon experimental set-up ............ 11

Appendix B: Heat load due to thermal leaks in the thermosyphon set-up ......................................... 13

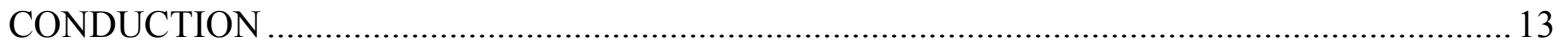

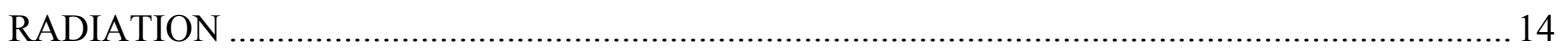

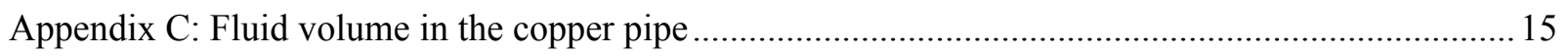

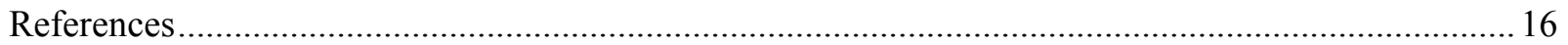




\section{Figures}

Figure 1: Model of the thermosyphon set-up at PNNL....................................................................2

Figure 2: Experimental set-up showing the vacuum cylinder that encloses the evaporator tube and the elbow to the vertical chamber (at the right) that leads up to the condenser........................................... 3

Figure 3: Evaporator tube with heater assembly in the vacuum jacket............................................... 4

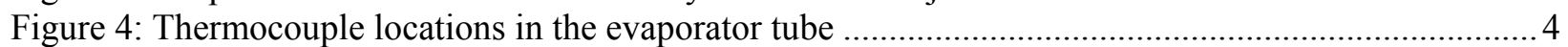

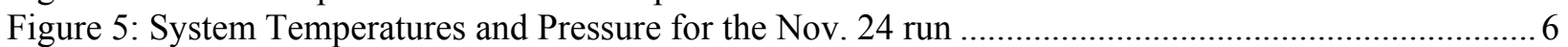

Figure 6: Boiling curve for nitrogen and PT states for the Nov. 24 run. .................................................. 6

Figure 7: Temperature of TC1 and TC5 for the Dec. 8,9 experiment run. .......................................... 7

Figure 8: Temperature drop across thermal joint versus tip heater power................................................. 8

Figure 9: Temperature gradient versus power applied to tip heater...................................................... 8

Figure 10: Thermosyphon calculated and expected performance.......................................................... 9 


\section{Experimental set-up}

The thermosyphon has three main components: a condenser, an evaporator, and a vertical column that connects these two modules. The condenser for this experimental system is a mechanically cooled vertical copper rod acting as a cold finger. The mechanical cooler (cold head) is a helium refrigerator capable of extracting $\sim 60 \mathrm{~W}$ at $80 \mathrm{~K}$. The cooler is thermally coupled to the cold finger through an indium layer. The dimensions of the condenser rod are $0.0127 \mathrm{~m}$ diameter $(1 / 2 \mathrm{inch})$ and $0.254 \mathrm{~m}(10$ inches) long. The evaporator is a horizontal copper pipe with a length that matches that of the pipe going through the MAJORANA DEMONSTRATOR shield. The dimensions of the evaporator tube are $0.0254 \mathrm{~m}$ diameter ( 1 inch), $0.0032 \mathrm{~m}$ thickness $(1 / 8 \mathrm{inch})$ and $1.016 \mathrm{~m}$ (40 inches) long. The experimental set up allows for the evaporator tube to be tilted in order to explore performance limits and impact of a slight downward slope toward the evaporator tip where the primary heat load is applied. Figure 1 shows the computer-aided design model with the outer vacuum jacket shown transparent for clarity. Figure 2 shows the experimental set-up at PNNL with the vacuum cylinder that encloses the evaporator tube and the elbow to the vertical chamber (at the right) that leads up to the condenser. 


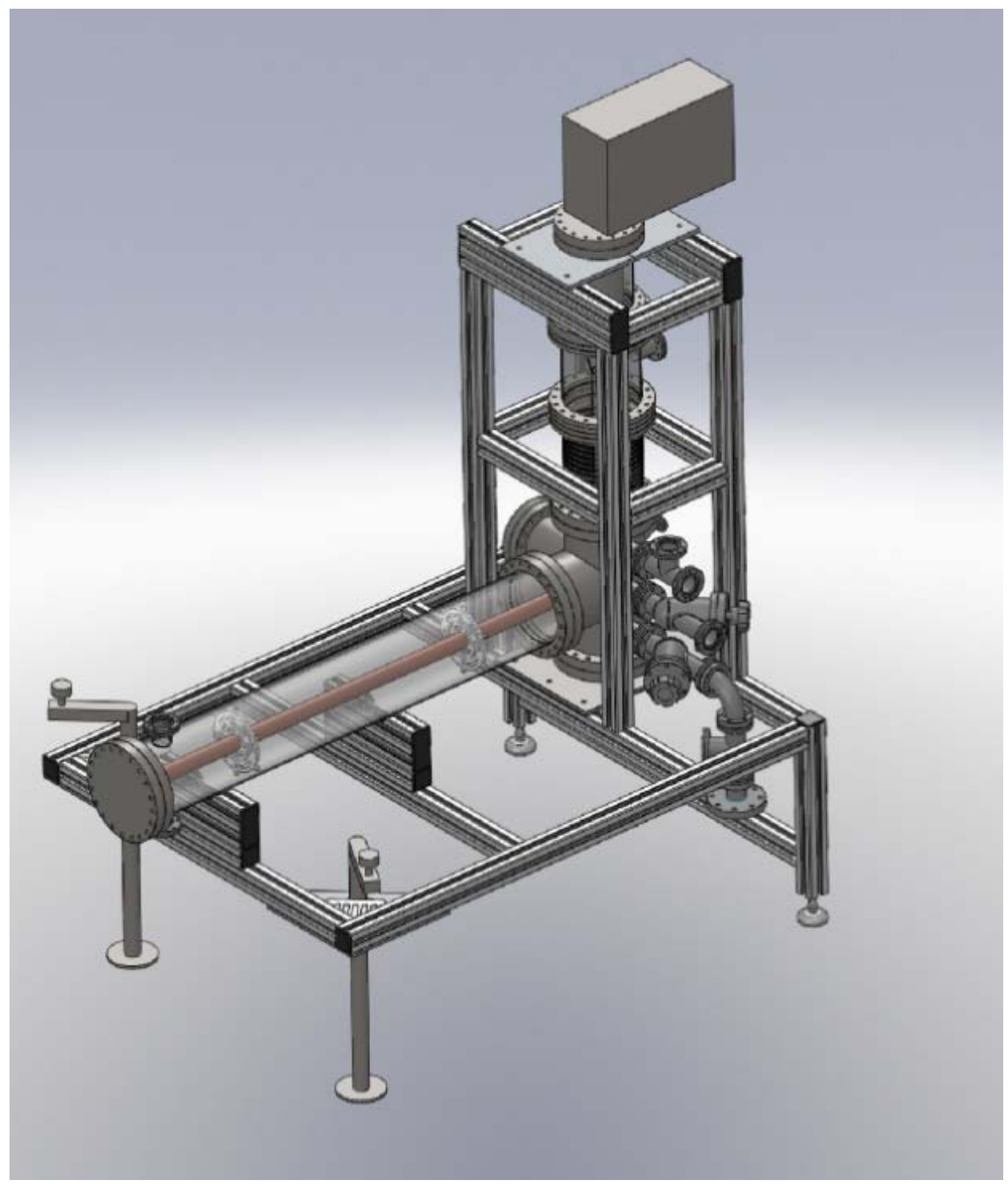

Figure 1: Model of the thermosyphon set-up at PNNL. 


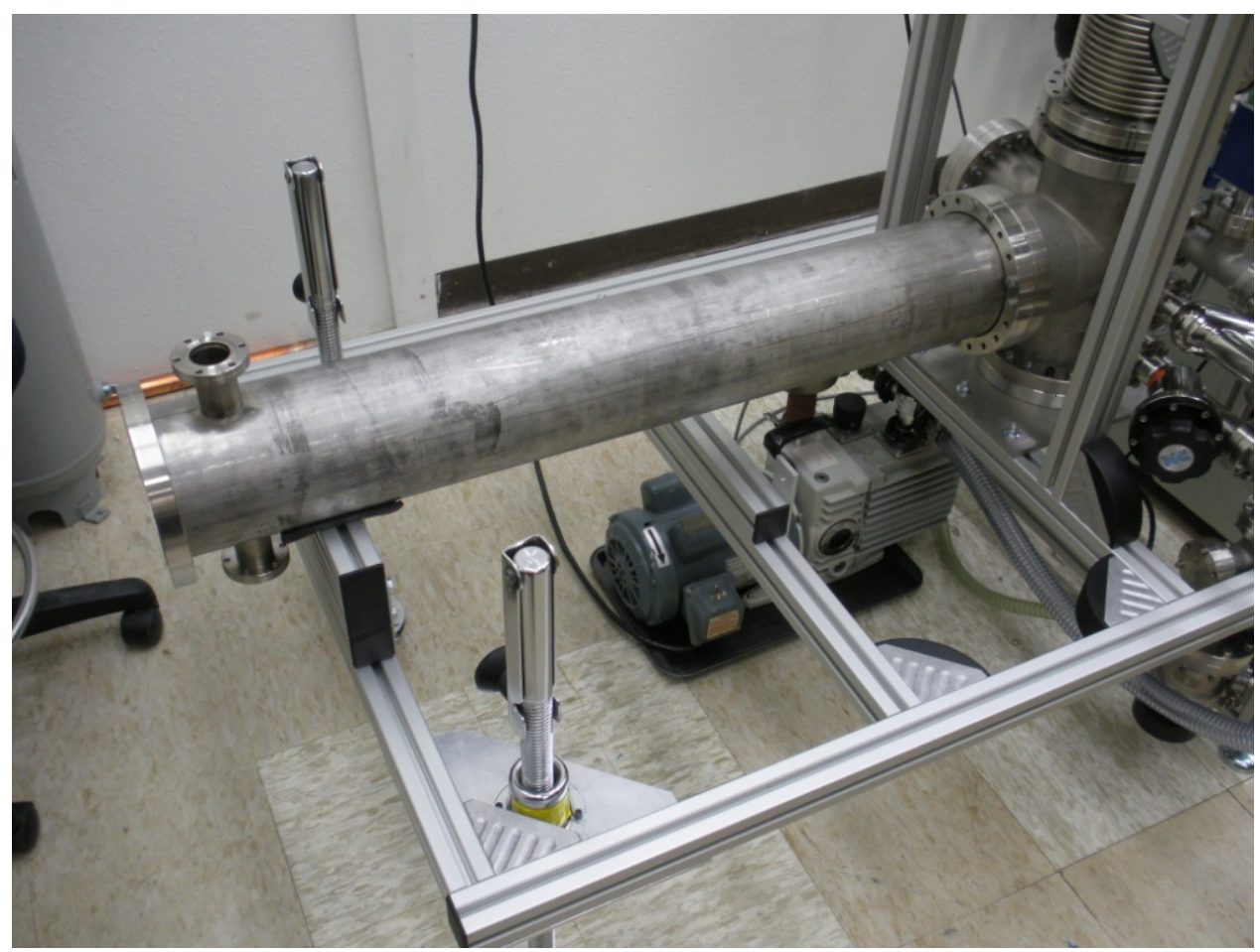

Figure 2: Experimental set-up showing the vacuum cylinder that encloses the evaporator tube and the elbow to the vertical chamber (at the right) that leads up to the condenser.

The heat transfer in the thermosyphon is carried out by the two-phase nitrogen in the system. The thermosyphon tube volume is connected to an external pressurized nitrogen tank (ballast tank) with a volume much larger than that of the tube so that the system can be initially charged with a moderate pressure of nitrogen gas (at STP) and sealed prior to cool down. The amount of nitrogen remains constant during operation. The total volume of nitrogen is equal to the internal volume of the evaporator tube plus the volume of the vertical column connected to the condenser plus the volume of the nitrogen gas ballast tank connected to the system (approximately 37.81 ). As the system is cooled and nitrogen gas condenses to liquid phase the pressure in the system falls to near atmospheric pressure. Using a large volume ballast tank reduces the pressure requirements of the thermosyphon tube when all of the nitrogen is in the gaseous state, reducing the engineering and safety challenges of a highly pressurized system. The system operating point is monitored using a pressure gauge located on the ballast tank to thermosyphon body connection line.

An adjustable electric heater has been placed at the tip of the tube to emulate the heat load created by the detector module, as shown in Figure 3. The adjustable heater at the tip of the evaporator tube has been used to apply different heat loads within the range of interest, from $0 \mathrm{~W}$ to $25 \mathrm{~W}$. The two-phase nitrogen system's operating point is regulated by adjusting the cold head temperature using a second heater embedded in the cold head. Four thermocouples have been placed along the evaporator tube. Figure 4 shows the location of the thermocouples in the evaporator tube. The thermocouple TC1 is located 4 inches away from the tip of the tube, TC2 is located 21 inches away from the tip, TC4 is located 36 inches away from the tip, and TC5 is located at the elbow leading to the condenser. Additional thermocouples are located within one of the PEEK supports for the evaporator tube (TC3) and at the condenser (TC6). 


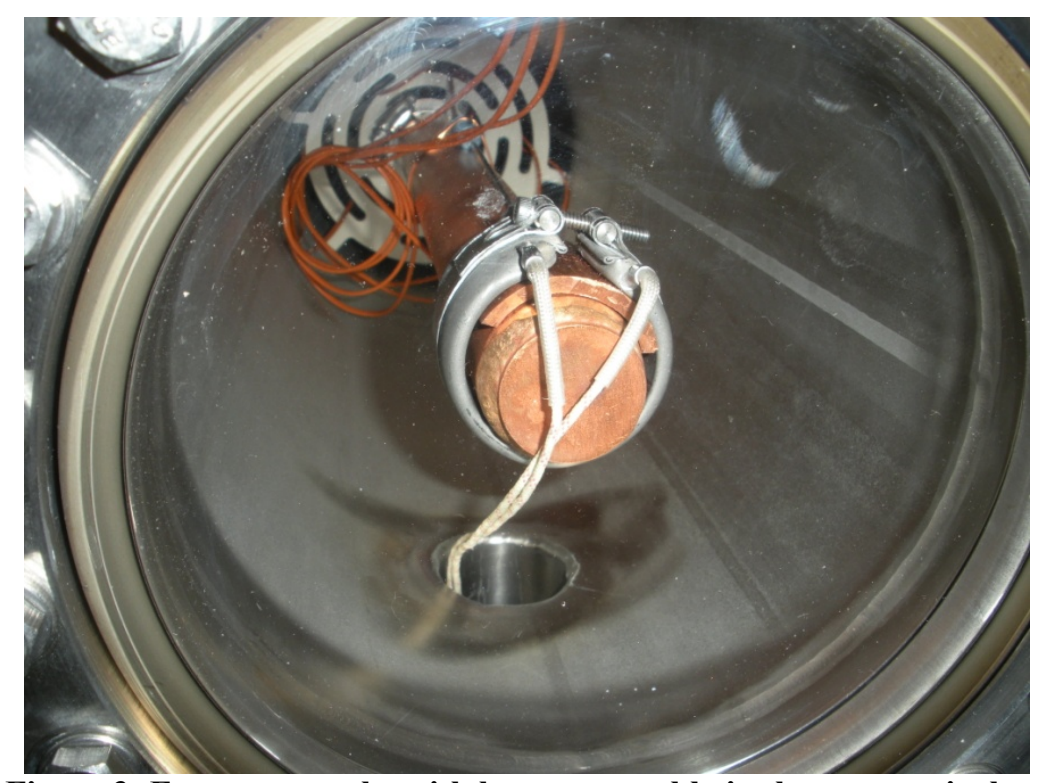

Figure 3: Evaporator tube with heater assembly in the vacuum jacket.

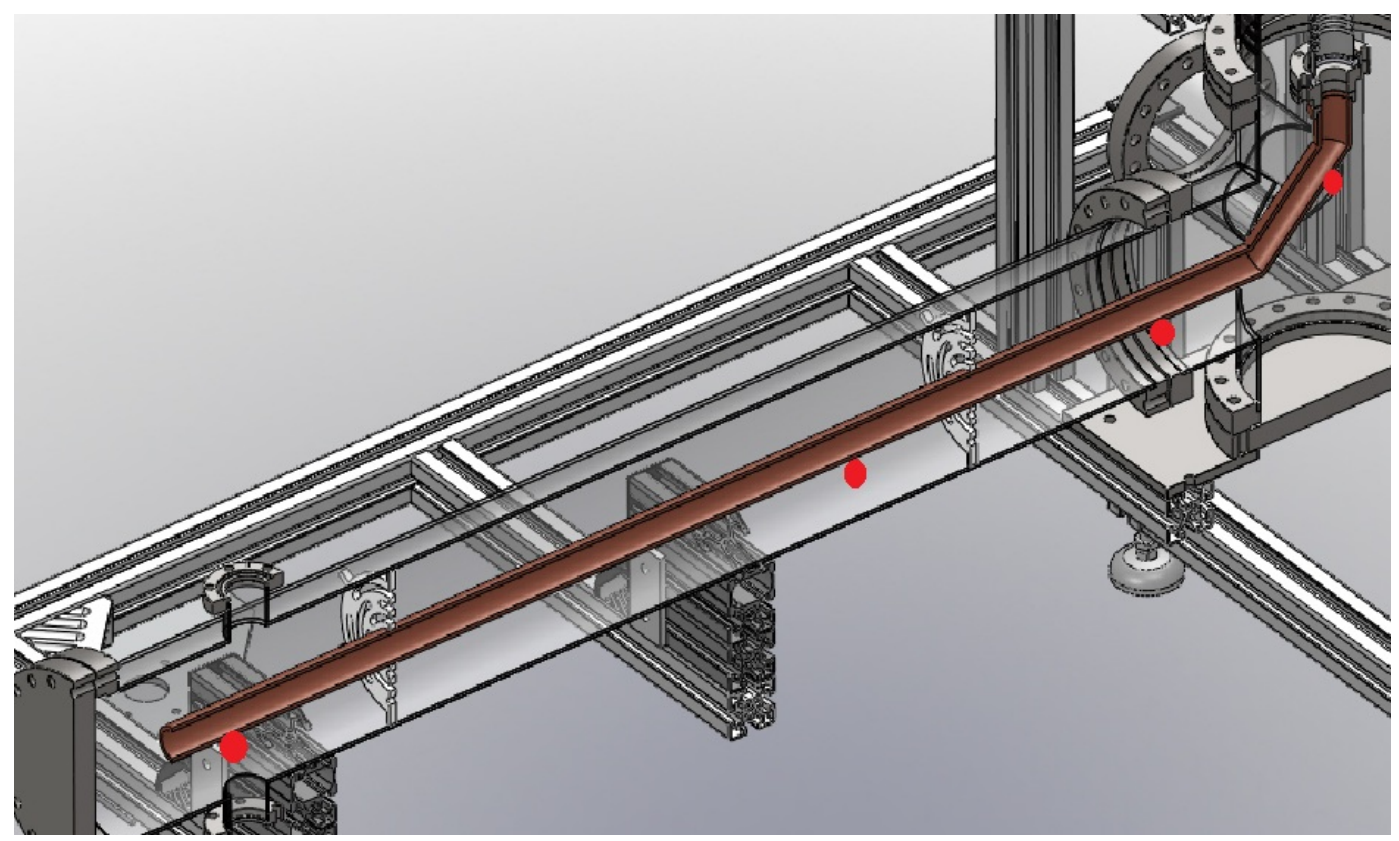

Figure 4: Thermocouple locations in the evaporator tube 


\section{Experimental results}

The experimentation with the system started using 15 psig at room temperature of nitrogen in the system. The amount of nitrogen was increased to $50 \mathrm{psig}$ at standard temperature and pressure for the majority of the measurements presented. Table 1 shows data relating to each of the thermosyphon runs. For each unique operating point data was collected for at least 3 hours after a stable operating condition was established. The experimental data presented in Table 1 are for steady-state system operations. System stability was confirmed using the pressure reading. The operating pressure was kept in the range 0 to 4 psig representative of anticipated operating conditions when the cold head is replaced with an open liquid nitrogen reservoir to cool the condenser. The observed temperatures in the thermosyphon are consistent with the boiling point of nitrogen in this pressure range.

\begin{tabular}{|l|l|l|l|l|l|l|l|}
\hline Date & \multirow{2}{*}{$\begin{array}{l}\mathrm{N}_{2} \text { load } \\
\text { (psig, 20 }\end{array}$} & \multirow{2}{*}{$\begin{array}{l}\text { Evap. tilt } \\
(\text { degrees) }\end{array}$} & \multicolumn{2}{|c|}{ Power Settings (Watts) } & \multicolumn{3}{|c|}{ Temperatures (Kelvin) } \\
\cline { 4 - 8 } & & $\begin{array}{l}\text { Cold head } \\
\text { heater }\end{array}$ & $\begin{array}{l}\text { Evap. tip } \\
\text { heater }\end{array}$ & Cold head & $\begin{array}{l}\text { Evap. tip } \\
\text { (TC1) }\end{array}$ & $\begin{array}{l}\text { Evap. elbow } \\
\text { (TC5) }\end{array}$ \\
\hline Nov. 12 & 15 & 3 & 52 & 5 & 69 & 81.8 & 80.1 \\
\hline Nov. 24 & 49 & 0 & 9.3 & 25 & 42 & 83.6 & 78.4 \\
\hline Dec. 01 & 49 & 0 & 15 & 22.3 & 45 & 84.3 & 79.0 \\
\hline Dec. 02 & 49 & 0 & 30 & 16 & 50 & 81.1 & 76.5 \\
\hline Dec. 03 & 49 & 0 & 40 & 10 & 60 & 83.5 & 78.5 \\
\hline Dec. 04 & 49 & 0 & 58 & 0 & 72 & 82.5 & 78.8 \\
\hline Dec. 06 & 49 & 0 & 48 & 5 & 65 & 82.7 & 78.2 \\
\hline
\end{tabular}

Table 1: Thermosyphon set-up operating parameters for steady-state runs. Run times were 3-4 hours after stable operation was established each time the operating point was adjusted.

Figure 5 shows the pressure and temperature of the nitrogen mass in the system. The graphs show how the system evolved during cool down for the November 24 run. For the November 24 run the starting pressure was $\sim 50 \mathrm{psig}$. The temperature reading starts to drop in the thermocouple closer to the cold head, TC5, about two hours after the run start. As the system cools the gas temperature decreases and the density increases resulting in the gradual pressure drop seen from 0-2 hr. At this point liquid begins to form at the condenser and drop to the evaporator where it is re-vaporized almost immediately so that no significant liquid volume is present in the system, but heat transfer from the evaporator to the condenser rises dramatically as seen by the rapid drop in the reading for TC6. As the liquid reaches further along the evaporator similar drops are seen for TC4, TC2 and finally TC1. At 4-4.5 hours the entire evaporator has a small amount of liquid in it and the system begins to convert more gas to liquid, resulting in a dramatic drop in pressure and an associated temperature drop as the boiling point of the two-phase system decreases. Figure 6 shows the boiling curve for nitrogen gas (data taken from [1]) and the pressure temperature states for the different points where temperature is measured in the thermosyphon. The error in the temperature measurement has been considered to be equal to the room temperature cross calibration error of the thermocouples; the cross calibration at liquid nitrogen temperature has not been measured and may be larger than that at room temperature. The correlation of the evaporator tip temperature with the nitrogen boiling temperature at the system pressure indicates that the thermosyphon is, in fact, operating as a two-phase cooling system. 


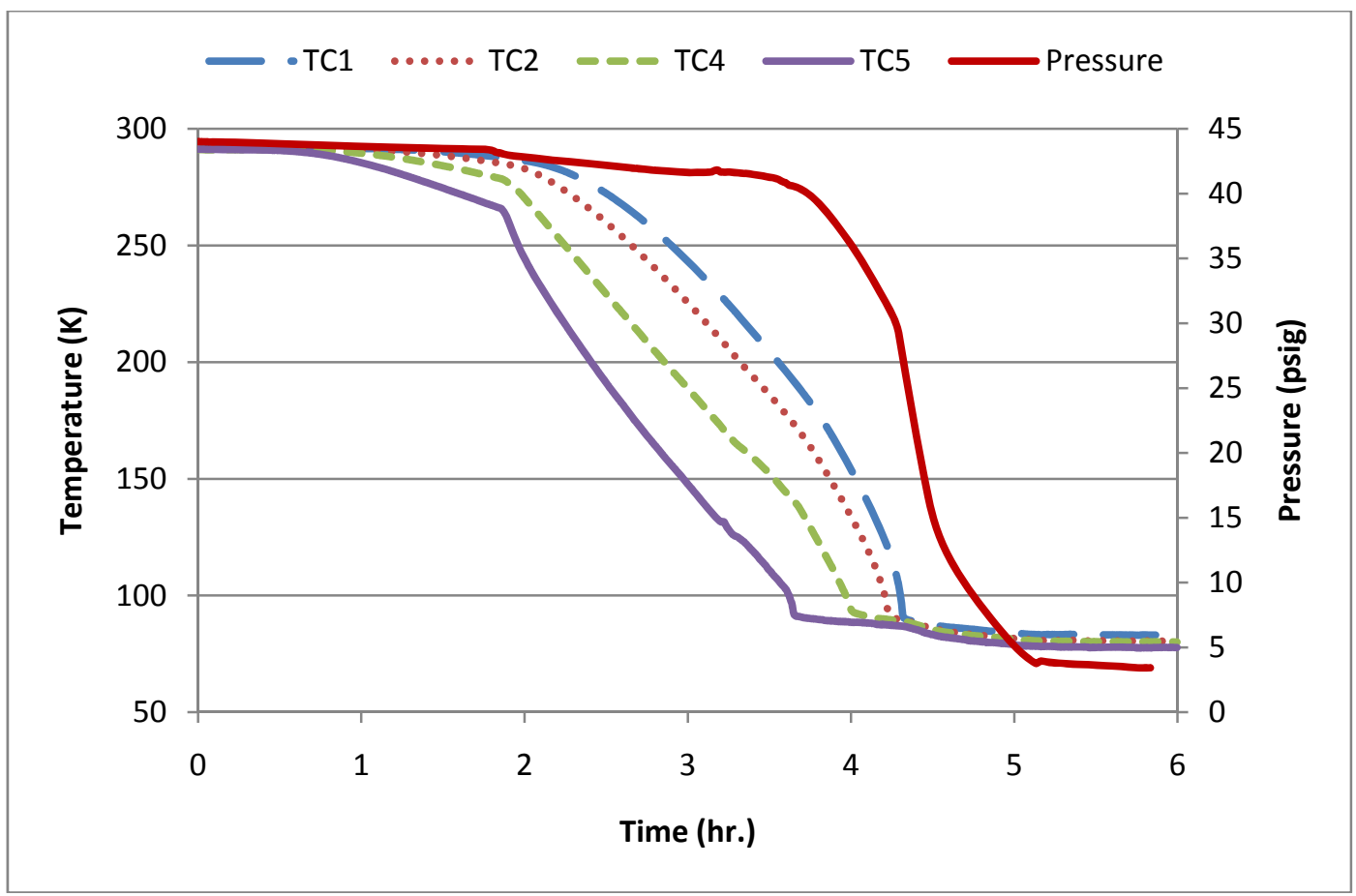

Figure 5: System Temperatures and Pressure for the Nov. 24 run

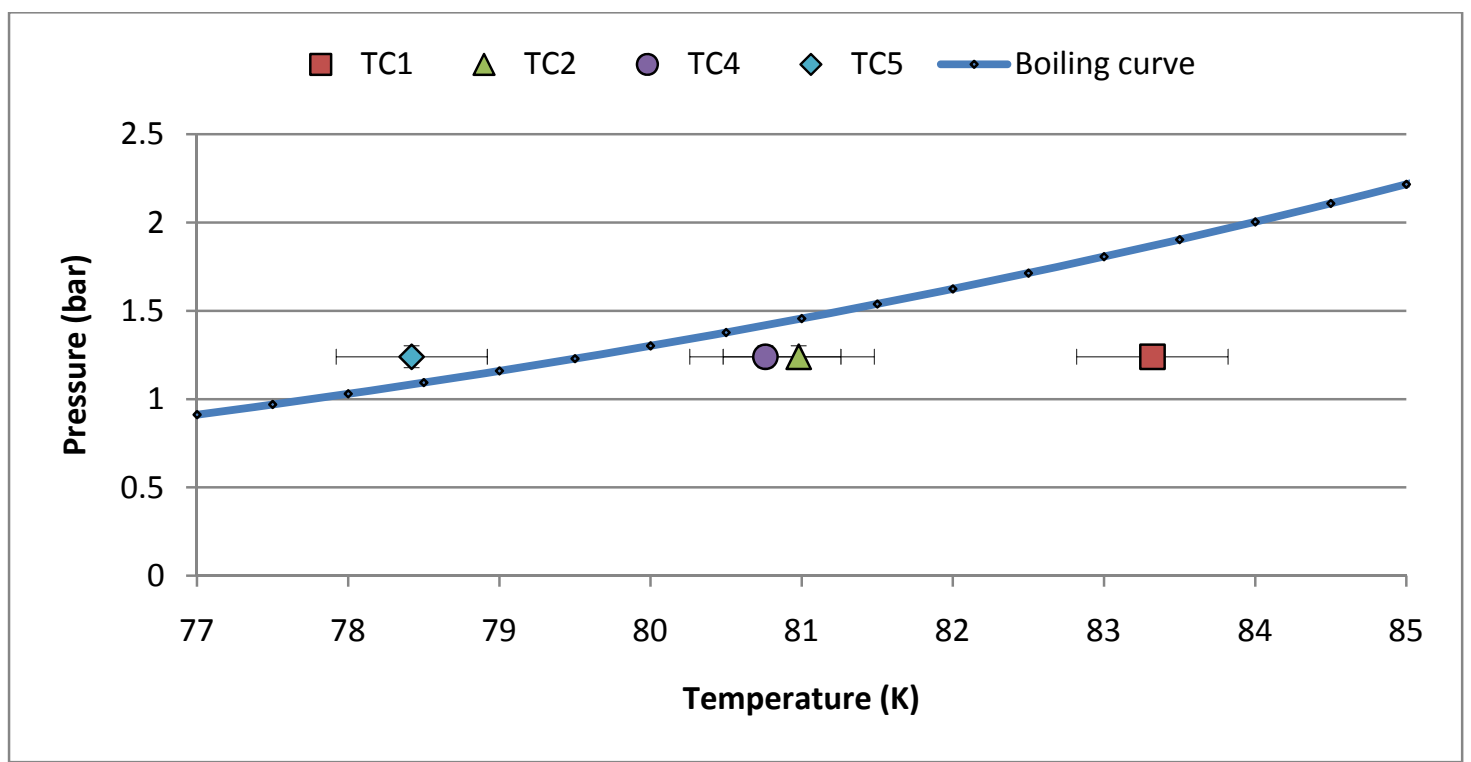

Figure 6: Boiling curve for nitrogen and PT states for the Nov. 24 run.

Figure 7 shows the temperature difference between the tip of the evaporator tube and the base of the vertical column leading to the condenser as the system was cooled down. These samples were recorded during an extended run where the system was initially set to operate as it did in the December 4 run. The purpose was to evaluate the system cool down time without any heat load applied at the tip. For this run the cold head was set at the beginning of the run to $58 \mathrm{~W}$ and was not altered during the cool down process. This operating condition with stable heat sink capacity at the condenser end of the thermosyphon simulates the Dewar conditions. The graph shows an initial low temperature gradient 
when the experiment starts. This is the equilibrium state when the cold head is not in operation. The temperature gradient in the evaporator tube at room temperature was $1.0 \mathrm{~K}$. The temperature difference began to grow as liquid reached the elbow below the condenser, but had not yet reached the tip of the thermosyphon. As the evaporator tube cooled and the liquid continued to reach further towards the tip the temperature difference reached $26 \mathrm{~K}$. This is the maximum gradient across the thermosyphon. At this point conduction through the copper walls of the evaporator tube begins to cool down the tip of the evaporator tube (TC1), and approximately 20 hours later the evaporator tube cools down enough that liquid reaches the tip of the tube. Once this occurs, the pressure in the system starts to drop, which means that more liquid is forming and pooling in the evaporator tube. The time for the thermosyphon to cool down and reach a two-phase steady-state equilibrium is approximately 32 hours. The temperature gradient for steady-state cold operations is discussed further below.

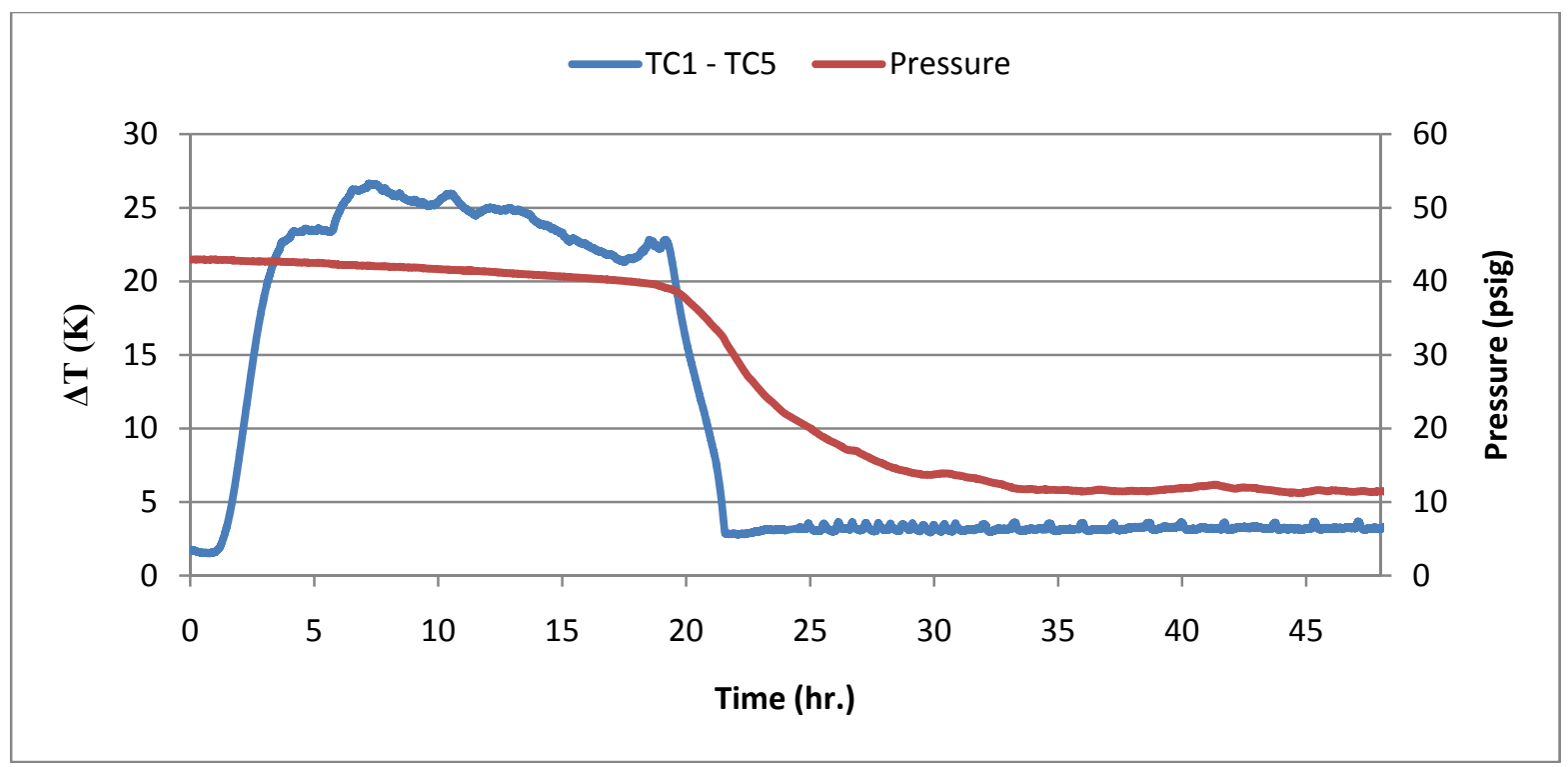

Figure 7: Temperature of TC1 and TC5 for the Dec. 8,9 experiment run.

The system behavior with different heat loads applied to the tip of the evaporator tube was evaluated in this experiment. The cold head trim heater was adjusted at each tip heat power setting to achieve a stable operating point with a pressure of 0-4 psig. Figure 9 shows the temperature drop across the joint between the thermosyphon and the cold head versus the power applied at the tip. The slope of the linear fit $(0.86$ $\mathrm{W} / \mathrm{K}$ ) provides an estimate of the thermal resistance of the bolted interface between the condenser and cold head. The heat leaking into the system as indicated from this linear regression is estimated to be 9.4 $\mathrm{W}$. This number compares to the previous thermosyphon assembly that had a $17.5 \mathrm{~W}$ heat leak. The improvement in mainly due to the three layers of aluminized Mylar infrared shielding wrapped between the cold thermosyphon tube and the warm steel vacuum tube. 


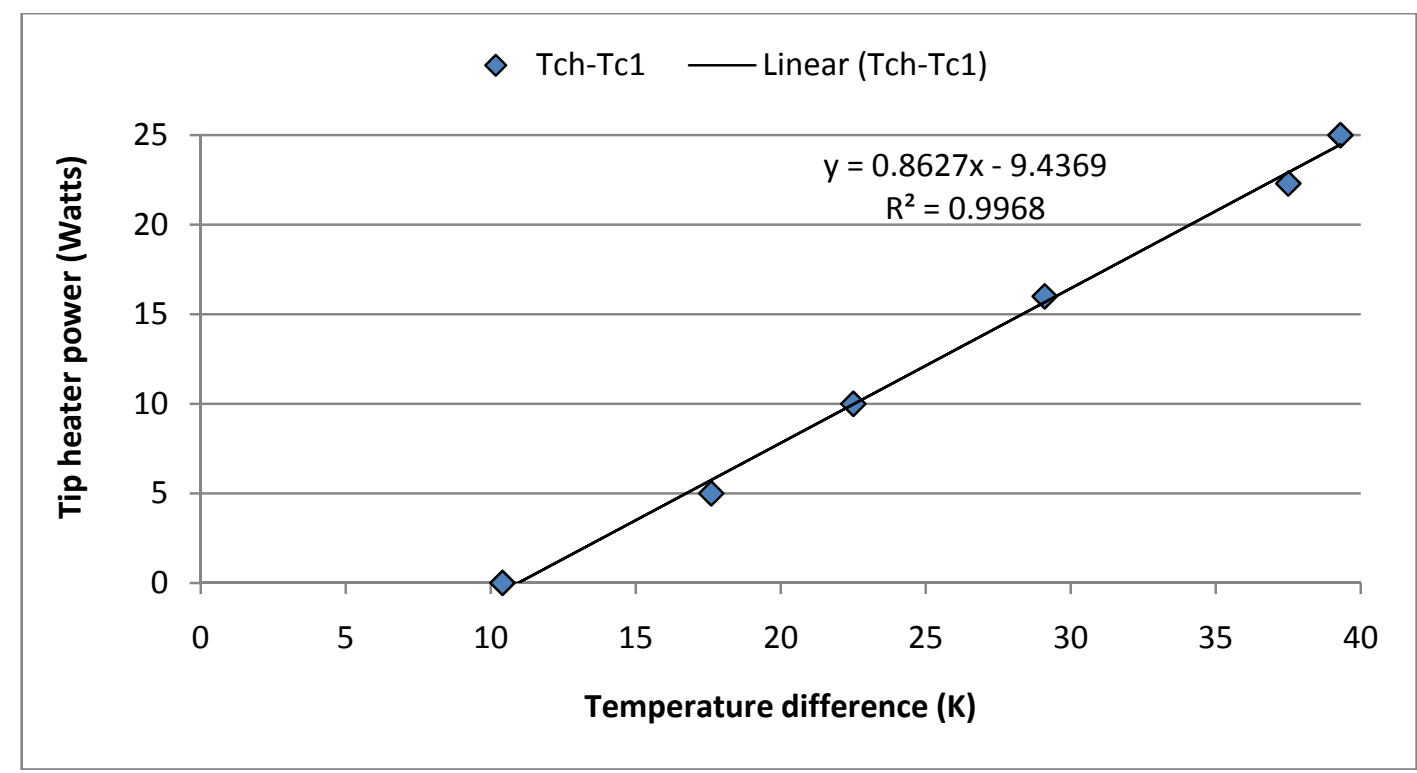

Figure 8: Temperature drop across thermal joint versus tip heater power.

The temperature drop across the evaporator tube versus applied power at the tip of the evaporator has also been analyzed. Figure 10 shows the gradient in temperature for the different temperature sensor locations. A cross-calibration of the thermocouples at liquid nitrogen temperatures is required to evaluate whether the absolute differences are accurate. Note that the cross-calibration at room temperature indicates $\sim 0.5 \mathrm{~K}$ differences between sensors. The pressure error bar presented is matched to the sensitivity of 1 psig of the pressure gauge. From this data one can state that the temperature gradient across the thermosyphon increases with the tip heat load, but changes by only $1 \mathrm{~K}$ over a $25 \mathrm{~W}$ power range, indicating satisfactory temperature stability over a broad range of input power. Assuming that cross-calibrations are not significant at this temperature it appears that the thermosyphon could have a few degrees Kelvin gradient along its length.

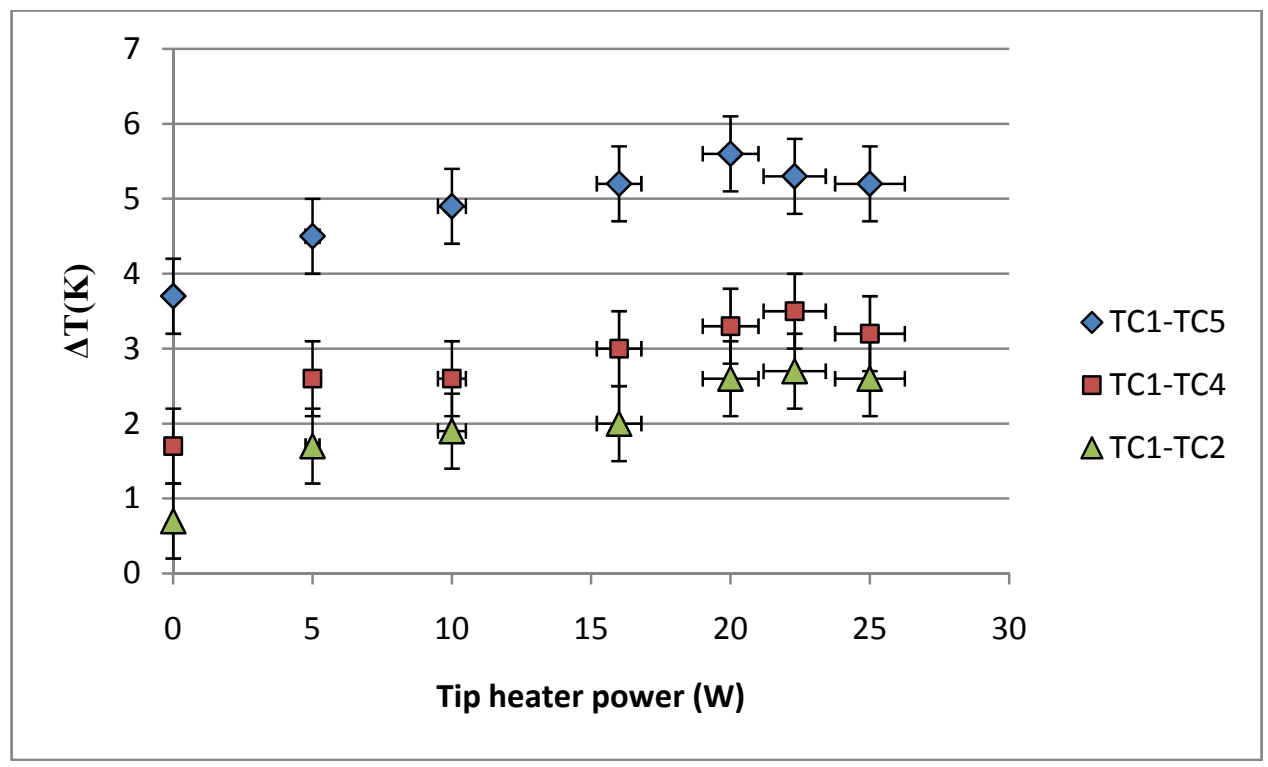

Figure 9: Temperature gradient versus power applied to tip heater 


\section{Thermal analysis}

The thermal model for the thermosyphon is fairly simple. The cold head is a model 1050 single stage Cryodyne refrigerator [3]. Figure 11 shows the typical performance of the Cryodyne 1050 cold head in red taken from the manufacturer specifications. It is important to notice the performance curve indicates that the amount of heat evacuated by the cold head is a non-linear function of the temperature of the cold head, falling significantly as the cold head temperature is reduced. This is in contrast to the proposed liquid nitrogen bath for the MAJORANA DEMONSTRATOR, which is expected to operate at fixed temperature, with a capacity vastly greater than the maximum heat load. The blue curve of Figure 11 represents the experimental data points. The experimental value for the heat is the sum of the power applied at the tip of the evaporator, to the cold head trim heater, and the heat leaking into the system (estimation from Figure 9). The discrepancy between the manufacturer's specifications and observed performance of the system is most likely due to errors in the operating curve of the cold head (which is a remanufactured unit).

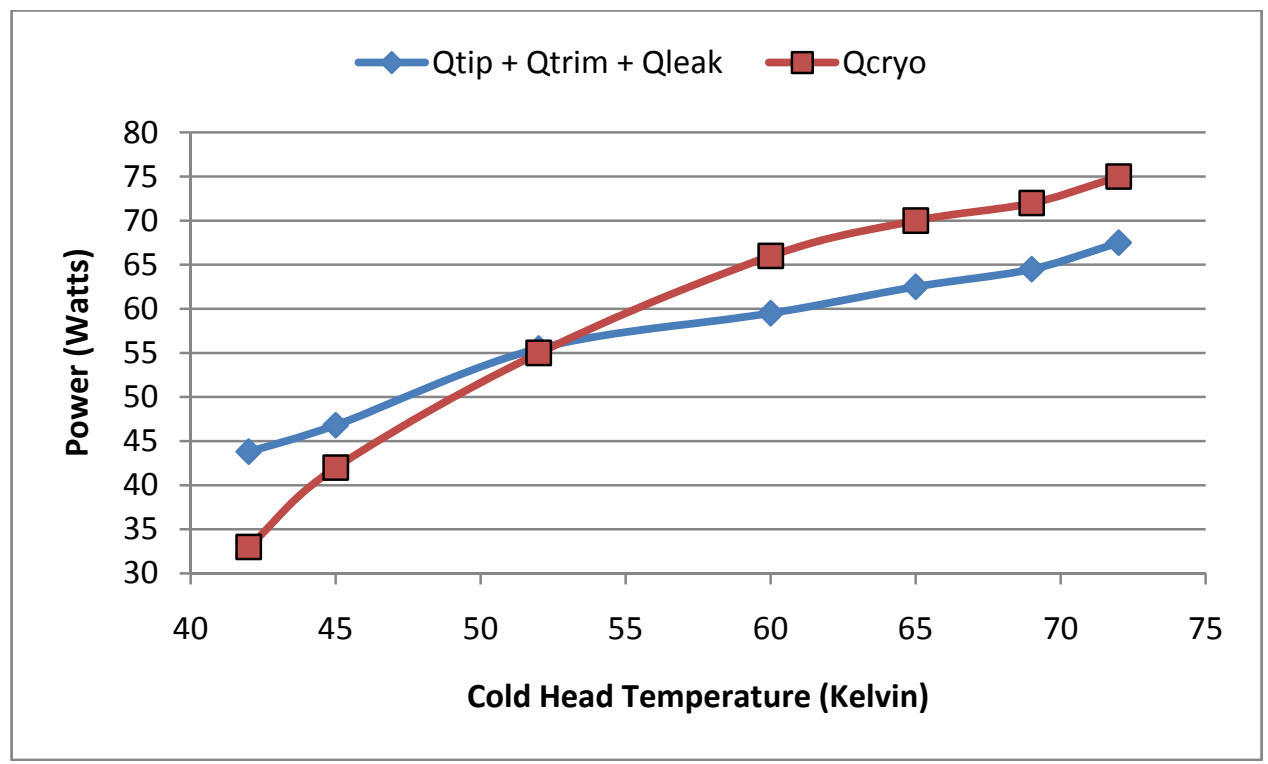

Figure 10: Thermosyphon calculated and expected performance.

The fluid flow in the system has been evaluated in Appendix A where we conclude that both the liquid and gas phases are in the laminar flow regime. This is preferable as turbulent flow could lead to vibration and ultimately microphonic noise in the electronics.

Appendix B presents the estimation of the value of different components that contribute to the heat load. The heat leaking into the thermosyphon has many contributing components. The main source is radiation from the warm vacuum chamber wall. Other components are conduction through the stainless steel bellows that connects the thermosyphon through the vacuum vessel to the nitrogen gas ballast tank, the nitrogen gas itself, and the PEEK supports for the evaporator tube which are in contact with the vacuum jacket. These calculations underestimate the heat leak derived experimentally from Figure 9, indicating that either some assumptions made are not valid or an additional heat path has not been included, for example conduction through the heater and thermocouple wiring or convective heat transfer between the cold gas inside the thermosyphon and the warm gas in the ballast tank. 


\section{Conclusions}

The experiment shows excellent operation of the thermosyphon up to an applied $25 \mathrm{~W}$ heat load at the tip of the evaporator plus the thermosyphon base heat load of $9.4 \mathrm{~W}$ even without a downward tilt of the evaporator tube toward the tip. The two-phase equilibrium was reached at different heat loads and the temperature and pressure were held stable during all experimental runs. The temperature gradient across the evaporator tube has been evaluated and characterized across the operating range of the thermosyphon. The main danger of this system is that the liquid film dries out due to excessive heat load and the temperature rises significantly at the tip of the evaporator tube. Operating at the maximum evaporator tip heat load achievable with the cold head $(25 \mathrm{~W})$ this behavior has not been observed in the experimental set-up; this heat load is greater than the anticipated heat load for the MAJORANA DEMONSTRATOR. Testing to higher heat loads to evaluate suitability for applications such as a tone-scale system will require a new condenser cooling system that eliminates the thermal interface between the thermosyphon condenser and the cold sink. The proposed design for the MAJORANA DEMONSTRATOR will address this critical design issue. 


\section{Appendix A: Convective heat transfer calculations for the thermosyphon experimental set-up}

The motion of the fluids (liquid and gas) inside the thermosyphon will be analyzed in this section.

Mass flow

The mass flow of nitrogen can be determined from the power dissipation required on the thermosyphon and the heat of vaporization of nitrogen:

Where:

$$
M F=\frac{q}{H_{\text {vap }} / \rho}
$$

- $\mathrm{q}$ is dissipated heat

- $\mathrm{H}_{\text {vap }}$ is heat of vaporization for nitrogen $(5.56 \mathrm{~kJ} / \mathrm{mol})$

- $\rho$ is nitrogen density $(28.01 \mathrm{~g} / \mathrm{mol})$

For a heat load of 25 Watts the result is MF $=1.26 \mathrm{E}-4 \mathrm{~kg} / \mathrm{s}$.

Reynolds Number

The type of flow (laminar or turbulent) for different situations where a fluid is in relative motion to a surface is given by the Reynolds number, $R e$ :

$$
R e=\frac{\rho V \mathrm{D}_{\mathrm{H}}}{\mu}
$$

Where:

- $\quad \rho$ is the density of the fluid $\left(\mathrm{kg} / \mathrm{m}^{3}\right)$

- $\mathrm{V}$ is the fluid velocity $(\mathrm{m} / \mathrm{s})$

- $\mathrm{D}_{\mathrm{H}}$ is the hydraulic diameter of the pipe $(\mathrm{m})$

- $\mu$ is the dynamic viscosity of the fluid (Pa.s)

The Reynolds number for the gas phase in the thermosyphon evaporator tube is calculated under the following assumptions:

- The gas is at $80 \mathrm{~K}$ with a density of $4.61 \mathrm{~kg} / \mathrm{m}^{3}$ and dynamic viscosity of $5.27 \mathrm{E}-6 \mathrm{~Pa}-\mathrm{sec}$

- $90 \%$ of the area of the evaporator cross section is occupied by the gas and the wetted length includes both the tube wall and liquid surface resulting in a hydraulic diameter of $2.35 \mathrm{~cm}$

- The fluid velocity of $0.06 \mathrm{~m} / \mathrm{s}$ is based on transport of sufficient nitrogen $(1.26 \mathrm{E}-4 \mathrm{~kg} / \mathrm{s})$ to remove 25 Watts of heat via heat of vaporization

The result is $R e_{\text {gas }}=1232$. When the value of the Reynolds number is below 2300, the system is considered to have laminar flow. The transition to turbulent flow will occur at approximately 47 Watts of heat load for this tube size, nitrogen temperature, and nitrogen liquid level. As the liquid level in the tube increases the flow velocity increases and the hydraulic diameter decreases with a net increase in the product. For example, when the thermosyphon tube is half filled with liquid the Reynolds number will increase by $18.8 \%$ and the critical heat load when the gaseous flow transitions from laminar to turbulent flow drops to approximately 39 Watts, still well above the heat load expected for the MAJORANA DEMONSTRATOR. 
The Reynolds number for the liquid flow is determined based on the following assumptions:

- The liquid is at $80 \mathrm{~K}$ with a density of $808 \mathrm{~kg} / \mathrm{m}^{3}$ and dynamic viscosity of $1.58 \mathrm{E}-4 \mathrm{~Pa}$-sec

- $10 \%$ of the area of the evaporator cross section is occupied by the liquid and the wetted length is only the contact area with the tube wall, resulting in a hydraulic diameter of $0.98 \mathrm{~cm}$

- The fluid velocity of $3.09 \mathrm{E}-3 \mathrm{~m} / \mathrm{s}$ is based on transport of sufficient nitrogen $(1.26 \mathrm{E}-4 \mathrm{~kg} / \mathrm{s})$ to remove $25 \mathrm{~W}$ of heat via heat of vaporization

The result is $R e_{\text {liquid }}=155$. As expected, the liquid flow is laminar.

\section{Prandtl number}

The Prandtl number is a dimensionless number approximating the ratio of momentum diffusivity (kinematic viscosity) and thermal diffusivity. It is defined as:

$$
\operatorname{Pr}=\frac{C_{p} \mu}{\kappa}
$$

Where:

- $\mu$ is the dynamic viscosity $\left(\mathrm{Pa}^{*} \mathrm{~s}\right)$

- $\mathrm{k}$ is the thermal conductivity $(\mathrm{W} /(\mathrm{Kg} \mathrm{m}))$

- $\quad \mathrm{c}_{\mathrm{p}}$ is the specific heat $(\mathrm{J} /(\mathrm{kg} \mathrm{K}))$

The Prandtl number for the gas phase is determined based on the following assumptions:

- The gas is at $80 \mathrm{~K}$ and 14.5 psia with a thermal conductivity of $8.0 \mathrm{E}-3 \mathrm{~W} / \mathrm{kg} * \mathrm{~m}$, a dynamic viscosity of 5.6E-6 Pa-sec and a specific heat of $2.1 \mathrm{e}-3 \mathrm{~J} / \mathrm{Kg} \mathrm{K}[1]$

The result is $\operatorname{Pr}_{\text {gas }}=1.47 \mathrm{E}-6$. For nitrogen gas at $80 \mathrm{~K}$, heat conduction is very effective compared to convection: thermal diffusivity is dominant. 


\section{Appendix B: Heat load due to thermal leaks in the thermosyphon set-up}

The conductive and radiative heat loads on the thermosyphon are documented below. The total estimated heat load is $3.1 \mathrm{~W}$, dominated by radiation from the warm vacuum vessel walls.

\section{CONDUCTION}

Heat leaks through conductive paths can be calculated using Fourier's Law for heat conduction :

Where:

$$
q=\frac{k * \Delta T * A}{L}
$$

- $\quad \mathrm{q}$ is the heat flow $(\mathrm{W})$

- $\quad \mathrm{k}$ is the thermal conductivity $(\mathrm{W} / \mathrm{m} * \mathrm{~K})$

- A is the area of the heat exchange surface $\left(\mathrm{m}^{2}\right)$

- $\quad \mathrm{L}$ is the length of the heat exchange volume $(\mathrm{m})$

- $\Delta \mathrm{T}$ is the temperature difference $(\mathrm{K})$

These points for conductive heat leaks are analyzed:

- Conduction of nitrogen vapor in bellows pipe

- Stainless steel wall of bellows pipe

PEEK supports for the evaporator tube

\section{Nitrogen vapor on bellow pipe}

Thermal conductivity of nitrogen vapor: $\mathrm{k}_{\mathrm{N}}(80 \mathrm{~K})=0.0077 \mathrm{~W} / \mathrm{m}-\mathrm{K}$

Temperature difference $(\max ): \Delta \mathrm{T}=300-80=220 \mathrm{~K}$

Bellows pipe: diameter 0.925 in, thickness 0.008 in, length 18 in

Nitrogen gas area: $\mathrm{A}=0.0017 \mathrm{~m}^{2}$

Length of warm-to-cold path: $\mathrm{L}=0.45 \mathrm{~m}$

Conductive heat load through $\mathrm{N}_{2}$ gas, $\mathrm{q}_{\mathrm{gas}}=0.006 \mathrm{~W}$

\section{Bellow pipe}

The bellow pipe is made of stainless steel.

Thermal conductivity of stainless steel: $\mathrm{k}_{\mathrm{ss}}(80 \mathrm{~K})=8.4 \mathrm{~W} / \mathrm{m}-\mathrm{K}, \mathrm{k}_{\mathrm{ss}}(300 \mathrm{~K})=15 \mathrm{~W} / \mathrm{m}-\mathrm{K}$

Temperature difference $(\max ): \Delta \mathrm{T}=300-80=220 \mathrm{~K}$

Bellows pipe: diameter 0.925 in, thickness 0.008 in, length 18 in

Stainless steel area: $\mathrm{A}=1.5 \mathrm{E}-5 \mathrm{~m}^{2}$

Length of warm-to-cold path: $\mathrm{L}=1.4 \mathrm{~m}$ ( 3 times bellows length to account for convolutions)

Conductive heat load through stainless steel bellows, $\mathrm{q}_{\mathrm{ss}}=0.035 \mathrm{~W}$

PEEK supportsThe thermosyphon supports are made of PEEK (poly-ether-ether-ketone)

Thermal conductivity of PEEK: $\mathrm{k}_{\mathrm{ss}}$ (room temperature) $=0.25 \mathrm{~W} / \mathrm{mK}$

Temperature difference $(\max ): \Delta \mathrm{T}=300-80=220 \mathrm{~K}$

PEEK area (maximum contact area with vacuum jacket): $\mathrm{A}=4.84 \mathrm{E}-4 \mathrm{~m}^{2}$

Length of warm-to-cold path: $\mathrm{L}=0.084 \mathrm{~m}$

Conductive heat load through the two peek supports, $\mathrm{q}_{\mathrm{PEEK}}=0.317 \mathrm{~W}$ 


\section{RADIATION}

\section{Radiation losses from warm walls}

Calculation of radiation losses along the copper pipe wrapped with aluminized Mylar.

Emissivity of Mylar: $\varepsilon_{\text {mylar }}=0.03$.

The first layer of Mylar is wrapped close to a diameter near 1.4 inches.

$\mathrm{A}_{\text {copper }}=\pi * 1.4 \mathrm{in} * 52.3 \mathrm{in}=230.0 \mathrm{in}^{2}$

Outside area of copper tube

$\mathrm{A}_{\text {copper }}=\pi^{*} 1.3 \mathrm{in} * 52.3 \mathrm{in}=213.6 \mathrm{in}^{2}$

Inner surface area of stainless steel tubing NOT including vertical bellows or cryohead.

$\mathrm{A}_{\mathrm{ss}}=\pi^{*} 1.3 \mathrm{in}^{*} 10.0 \mathrm{in}=40.8 \mathrm{in}^{2}$

Outside surface area of cold head stainless in vacuum

$\mathrm{A}_{\text {cryo }}=\pi * 2.75 \mathrm{in} * 7 \mathrm{in}=60.47 \mathrm{in}^{2}$

Stefan-Boltzmann constant known

$\sigma=5.67 * 10^{-8} \mathrm{~W} / \mathrm{m}^{2} * \mathrm{~K}^{4}$

Arrangement and emissivity factors obtained from [4] Table 37.1 provides the grey body shape factor for concentric spheres or infinite cylinders with spectral (mirror like) radiation:

$$
F_{\text {surf1_surf } 2}=\frac{1}{\frac{1}{\operatorname{surf1}}+\left(\frac{1}{\operatorname{surf2}}-1\right)\left(\frac{A_{\text {surf } 1}}{A_{\text {surf } 2}}\right)}
$$

The ratio of areas was replaced by the ratio of diameters.

An inner diameter of 5.76 inches was used for the 6 inch stainless steel vacuum jacket tube.

1.5 inches is used for the inner stainless tube, and 1.3 inches is used for the copper.

The shape factor for the case when copper is inside stainless with Mylar coatings.

$\mathrm{F} 1=0.025$

The shape factor for the case when polished stainless is inside unpolished stainless with Mylar coatings. $\mathrm{F} 2=0.024$

The transition bellows is an irregular geometry and calculating radiation is difficult. A simplified calculation was made assuming the 18 inch bellows expands to 20 inches inside due to pressure differentials. The bellows conduction calculation has been divided into two sections. A first section ( 8 inches) of the bellows has been considered to be centered within 1.5 inch diameter of the stainless T's. The remaining section of the bellows (12 inches) is considered to be centered in the vacuum jacket like the other stainless tube.

Stainless transition bellows part 1:

$\mathrm{F} 3=0.026$

Stainless transition bellows part 2:

$\mathrm{F} 4=0.019$

The vertical stainless bellows was modeled as a vertical section of 2 inch diameter unpolished stainless with Mylar coatings.

$\mathrm{F} 5=0.026$

The shape factor for the polished stainless cold head inside the 5 inch diameter unpolished stainless vacuum jacket with Mylar coatings.

$\mathrm{F} 6=0.019$

Inner and outer temperatures are averages. Changes of up to $10 \mathrm{~K}$ do not significantly affect the calculated heat load. $\mathrm{T} 1=293.5 \mathrm{~K} \mathrm{~T} 2=83 \mathrm{~K}$

Radiation heat load:

$\mathrm{q}_{\mathrm{rad}}=\mathrm{F} 1 *\left(\mathrm{~T} 1^{4}-\mathrm{T} 2^{4}\right) * \mathrm{~A}_{\text {copper }}+\mathrm{F} 2 *\left(\mathrm{~T} 1^{4}-\mathrm{T} 2^{4}\right) * \mathrm{~A}_{\text {ss_tube }}+\mathrm{F} 3 *\left(\mathrm{~T} 1^{4}-\mathrm{T} 2^{4}\right) * \mathrm{~A}_{\text {mylsr }}+\mathrm{F} 4 *\left(\mathrm{~T} 1^{4}-\mathrm{T} 2^{4}\right) * \mathrm{~A}_{\text {ss_bellow1 }}+$ $\mathrm{F} 5^{*}\left(\mathrm{~T} 1^{4}-\mathrm{T} 2^{4}\right)^{*} \mathrm{~A}_{\text {ss_bellow2 }}+\mathrm{F} 6^{*}\left(\mathrm{~T} 1^{4}-\mathrm{T} 2^{4}\right)^{*} \mathrm{~A}_{\mathrm{v}_{-} \text {bellows }}+\mathrm{F} 7 *\left(\mathrm{~T} 1^{4}-\mathrm{T} 2^{4}\right)^{*} \mathrm{~A}_{\mathrm{ss} \_ \text {cryo }}=2.84 \mathrm{~W}$ 


\section{Appendix C: Fluid volume in the copper pipe}

The amount of nitrogen in the system remains constant. The ideal gas law was used to calculate the number of moles of nitrogen the system contains under the initial conditions;

Where:

$$
\mathrm{PV}=\mathrm{nRT} \quad(6)
$$

$\mathrm{P}=49 \mathrm{psig}=53.7 \mathrm{psia}=3.7 \mathrm{~atm}(11 / 24 / 10-12 / 5 / 10$ conditions $)$

$\mathrm{R}=0.0821 \mathrm{atmK}^{-1} \mathrm{~mol}^{-1}$

$\mathrm{T}=292 \mathrm{~K}(11 / 24 / 10-12 / 5 / 10$ conditions $)$

$\mathrm{V}=37.81$

The result is a total nitrogen content of $\mathrm{n}_{\mathrm{TOTAL}}=5.84$ moles

During operation the temperature drops once the cold head starts working. An equilibrium state is reached where the liquid and vapor phase coexist. Assuming that the nitrogen vapor remains at room temperature (the gas ballast tank is not cooled and dominates the total gas volume of the system), the amount of nitrogen in vapor phase can be derived from the pressure of the system using the ideal gas law;

(P and $\mathrm{T}$ from the 11-24 Run)

$\mathrm{P}=4 \mathrm{psig}=18.7 \mathrm{psia}=1.3 \mathrm{~atm}(11 / 24 / 10$ run conditions $)$

$\mathrm{R}=0.0821 \mathrm{~atm} \mathrm{~K}^{-1} \mathrm{~mol}^{-1}$

$\mathrm{T}=292 \mathrm{~K}(11 / 24 / 10$ run conditions $)$

$\mathrm{V}=37.81$

The resulting nitrogen vapor content is $\mathrm{n}_{\text {vapor }}=2.05$ moles, and hence the remainder, 3.79 moles is liquid. Assuming that this amount of liquid sits completely in the evaporator tube, the volume of the liquid can be derived using the density of nitrogen;

$\mathrm{D}_{\text {liquid nitrogen }}(82 \mathrm{~K})=28.85 \mathrm{~mol} / \mathrm{l}$

$\mathrm{V}_{\text {nitrogen }}=0.131$

The total volume of the evaporator tube is $1.06 * 3.1416^{*} 0.0254^{2} \mathrm{~m}^{3}=2.0591$, so the liquid occupies $6.4 \%$ of the volume of the evaporator tube under these conditions.

The solid cut from a horizontal cylinder of length $L$ and radius $R$ by a single plane oriented parallel to the cylinder's axis of symmetry (i.e., a portion of a horizontal cylindrical tank which is partially filled with fluid) follows equation (8), taken from [2].

$$
V=L\left[R^{2} \cos ^{-1}\left(\frac{R-h}{R}\right)-(R-h) \sqrt{2 R h-h^{2}}\right]
$$

$\mathrm{h} \approx 0.0035 \mathrm{~m}=0.1$ inches

The fluid depth was approximately $11.5 \%$ of the evaporator tube diameter in the Nov. 24 run. 


\section{References}

[1]Span, R.; Lemmon, E.W.; Jacobsen, R.T.; Wagner, W.; Yokozeki, A., A Reference Equation of State for the Thermodynamic Properties of Nitrogen for Temperatures from 63.151 to $1000 \mathrm{~K}$ and Pressures to 2200 MPa, J. Phys. Chem. Ref. Data, 2000, 29, 6, 1361-1433

[2]Volume of a Horizontal Cylindrical Segment

http://mathworld.wolfram.com/HorizontalCylindricalSegment.html

[3] Helix Technology Corporation Model 1050 Cryodyne Refrigeration system.

http://www.helixtechnology.com

[4] Michael R. Lindeburg Mechanical Engineering Reference Manual for PE Exam, $11^{\text {th }}$ ed. Professional Publications, Inc. (2006) 


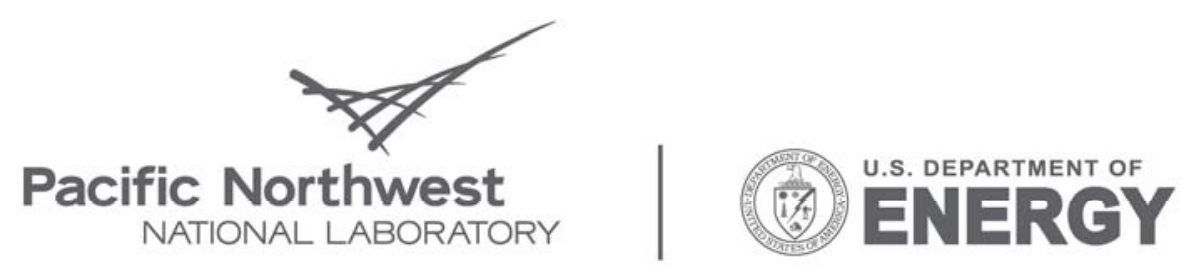

Proudly Operated by Battelle Since 1965

902 Battelle Boulevard

P.O. Box 999

Richland, WA 99352

1-888-375-PNNL (7665)

www.pnl.gov 